\title{
Intramale variation in sperm size: functional significance in a polygynous mammal
}

José Luis Ros-Santaella, Eliana Pintus, José Julián Garde

Studies concerning the relationships between sperm size and velocity at the intraspecific level are quite limited and often yielded contradictory results across the animal kingdom. Intramale variation in sperm size may represent a meaningful factor to predict sperm velocity, due to its relationship with the level of sperm competition among related taxa. Because sperm phenotype is under post-copulatory sexual selection, we hypothesized that a reduced intramale variation in sperm size is associated with sperm competitiveness in red deer. Our results show that low variation in sperm size is strongly related to high sperm velocity and normal sperm morphology, which in turn are good predictors of male fertility in this species. Furthermore, it is well known that the red deer show high variability in testicular mass but there is limited knowledge concerning the significance of this phenomenon at intraspecific level, even though it may reveal interesting processes of sexual selection. Thereby, as a preliminary result, we found that absolute testes mass is negatively associated with intramale variation in sperm size. Our findings suggest that sperm size variation in red deer is under a strong selective force leading to increase sperm function efficiency, and reveal new insights into sexual selection mechanisms. 
1 Title: Intramale variation in sperm size: functional significance in a polygynous mammal

\section{Abstract}

Studies concerning the relationships between sperm size and velocity at the intraspecific

5 level are quite limited and often yielded contradictory results across the animal kingdom.

6 Intramale variation in sperm size may represent a meaningful factor to predict sperm velocity,

7 due to its relationship with the level of sperm competition among related taxa. Because sperm

8 phenotype is under post-copulatory sexual selection, we hypothesized that a reduced intramale

9 variation in sperm size is associated with sperm competitiveness in red deer. Our results show

10 that low variation in sperm size is strongly related to high sperm velocity and normal sperm

11 morphology, which in turn are good predictors of male fertility in this species. Furthermore, it is

12 well known that the red deer show high variability in testicular mass but there is limited

13 knowledge concerning the significance of this phenomenon at intraspecific level, even though it

14 may reveal interesting processes of sexual selection. Thereby, as a preliminary result, we found

15 that absolute testes mass is negatively associated with intramale variation in sperm size. Our

16 findings suggest that sperm size variation in red deer is under a strong selective force leading to

17 increase sperm function efficiency, and reveal new insights into sexual selection mechanisms. 
23 José Luis Ros-Santaella ${ }^{1,2}$, Eliana Pintus ${ }^{3}$, José Julián Garde ${ }^{1}$

25 'SaBio IREC (CSIC-UCLM-JCCM), Campus Universitario s. n. 02071 Albacete, Spain

$26{ }^{2}$ Department of Animal Science and Food Processing, Faculty of Tropical AgriSciences, Czech

27 University of Life Sciences, Kamýcká 129, 16521 Prague 6 - Suchdol, Czech Republic.

$28{ }^{3}$ Department of Veterinary Sciences, Faculty of Agrobiology, Food and Natural Resources,

29 Czech University of Life Sciences, Kamýcká 129, 16521 Prague 6 - Suchdol, Czech Republic.

\section{Corresponding author:}

32 José Luis Ros-Santaella

33 Department of Animal Science and Food Processing, Faculty of Tropical AgriSciences.

34 Czech University of Life Sciences Prague.

35 Kamýcká 129, 16521 Prague 6 - Suchdol, Czech Republic.

36 E-mail: rossantaella@gmail.com

37 Phone: +420730192003 
43

\section{Introduction}

Sperm competition (competition between the sperm from two or more males for the fertilization of a given set of ova; Parker, 1998) is a powerful and taxonomically widespread selective force driving the evolution of sperm shape and function (Birkhead \& Møller, 1998; Immler, 2008; Pitnick, Hosken \& Birkhead, 2009; Pizzari \& Parker, 2009; Simmons \& Fitzpatrick, 2012). Sperm morphology is correlated with the different levels of sperm competition across the animal kingdom (for review see: Birkhead \& Immler, 2007; Pitnick, Hosken \& Birkhead, 2009). Across vertebrates, species with a low risk or lack of sperm competition are characterized by sperm pleiomorphism, high percentages of sperm abnormalities, and in extremes cases, sperm degenerative features (e.g. absence of the fibrous sheath and reduced midpiece; reviewed in: Van der Horst \& Maree, 2014). However, when sperm competition is intense, selection is thought to favor tight quality control (Birkhead \& Immler, 2007), for instance, by reducing the intramale variation in sperm size (e.g. insects: Fitzpatrick \& Baer, 2011; birds: Calhim et al., 2011; mammals: Šandera, Albrecht \& Stopka, 2013) and the percentage of sperm abnormalities (e.g. birds: Rowe \& Pruett-Jones, 2011; mammals: Gómez-Montoto et al., 2011; Lüpold, 2013), as well as by increasing the proportion of live sperm (e.g. insects: García-González \& Simmons, 2005). Intraspecific studies concerning the significance of intramale variation in sperm size are quite limited but also needed, because they can reveal relationships with sperm traits associated with sperm competitiveness and contribute to a better understanding of previously reported patterns across animal populations and species (Kleven et al., 2008; Laskemoen et al., 2013). success (Simmons \& Fitzpatrick, 2012; Fitzpatrick \& Lüpold, 2014), although factors 
66 determining sperm velocity are still not well established. Sperm size has been linked to sperm

67 velocity in a range of inter- and intraspecific studies, but these results have been inconsistent

68 (Humphries, Evans \& Simmons, 2008; Kleven et al., 2009; Lüpold et al., 2009a; Fitzpatrick \&

69 Lüpold, 2014; Simpson et al., 2014). For instance, in species with internal fertilization, the few

70 intraspecific studies investigating these kinds of relationships have yielded contradictory results

71 (e.g. mammals: Malo et al., 2006; Firman \& Simmons, 2010), even within the same species

72 (Passer domesticus: Helfenstein, Podevin \& Richner, 2009; Cramer et al., 2014). Recently,

73 Mossman et al. (2013) reported that low variation in the length of sperm components is

74 associated with a high percentage of motile sperm in humans. Therefore, studies concerning the

75 links between sperm kinetics and intramale variation in sperm size might provide a better

76 understanding of sperm functionality.

It is well known that high levels of sperm competition are related to increased relative

testes mass (Birkhead \& Møller, 1998). For this reason, relative testes mass has been widely used as a proxy measure of post-copulatory sexual selection (for review see: Simmons \& Fitzpatrick, 2012). The degree of elaboration of pre-copulatory traits also has been associated with testes size and both positive, negative or no relationships have been found (Merilä \& Sheldon, 1999;

82 Preston et al., 2003; Malo et al., 2005a; Simmons \& Emlen, 2006; Kelly, 2008). Moreover,

83 interspecific studies have shown that large relative testes mass is related to low variation in 84 sperm size both between and within males, such as in birds (Immler, Calhim \& Birkhead, 2008;

85 Kleven et al., 2008) and mammals (Šandera, Albrecht \& Stopka, 2013; Varea-Sánchez et al., 86 2014). However, intraspecific studies about the significance of the variation in testicular size are

87 scarce even though they might reveal interesting processes of sexual selection (Merilä \&

88 Sheldon, 1999; Schulte-Hostedde \& Millar, 2004; Liao et al., 2013). 
90 breeding groups that vary in membership from day to day (Clutton-Brock, Guinness \& Albon,

91 1982), such as in the red deer (Jarnemo, 2011; Pérez-González \& Carranza, 2011; Stopher et al.,

92 2011). In spite of being considered a polygynous mammal, red deer calves are sometimes

93 fathered by a non-dominant male (Pemberton et al., 1992), hinds show some degree of

94 promiscuity (Guinness, Lincoln \& Short, 1971), and the large numbers of aggregating females

95 should increase the mating opportunities of less competitive males because dominant males may

96 be unable to defend large harems (Pérez-González \& Carranza, 2011). Moreover, as a signal of

97 risk of sperm competition in this species, the red deer have large testes in relation to their body

98 size when compared with other species from the Cervidae family (Clutton-Brock, Guinness \&

99 Albon, 1982), and low within male variation in sperm size (Malo et al., 2006). Furthermore,

100 Malo et al. (2005a) reported that relative testes size in red deer was positively related to antler

101 size and complexity (pre-copulatory sexually selected trait), which in turn positively covaried

102 with sperm velocity (post-copulatory sexually selected trait).

The aims of this study were twofold. First, we examined the relationships between the

104 intramale variation in sperm size and sperm characteristics such as sperm velocity and normal

105 morphology, which are related to male fertility in this species (Malo et al., 2005b; Ramón et al.,

106 2013). Because sperm competition predicts intramale variation in sperm size across related taxa

107 (see references above), low variation in sperm size in red deer may confer an advantage in post-

108 copulatory sexual selection by enhancing sperm competitiveness. Second, taking into account

109 that testicular size is positively related to elaborate pre-copulatory traits (antlers, male-male

110 competition; Malo et al., 2005a) and shows high variability between stags (Martínez-Pastor et

111 al., 2005; Pintus, Ros-Santaella \& Garde, 2015), we hypothesized that variation in absolute testes 
112 mass is related to the intramale variation in sperm size as demonstrated at the interspecific level

113 in several animal taxa. Under these hypotheses, we expected to find relationships between

114 intramale variation in sperm size and sperm function, which can reveal new insights into sexual

115 selection processes.

116

117 Materials \& Methods

118 Animal sampling

119 This study was approved by the "Comité de Ética en Investigación de la Universidad de

120 Castilla-La Mancha”. All animals were handled in accordance with Spanish Animal Protection

121 Regulation RD53/2013, which conforms to the European Union Regulation 2003/65/CE. Stags

122 were legally hunted in their natural habitat in accordance with the harvest plan of the game

123 reserve. The harvest plans were made in accordance with Spanish Harvest Regulation, Law 2/93

124 of Castilla-La Mancha, which conforms to the European Union regulations. Landowners and

125 managers of the red deer populations gave permission to the authors to use the samples.

126 Samples were collected from 17 adult red deer (Cervus elaphus) males culled during the

127 breeding season (November-December 2010) in southern Spain. Due to the fact that stags were

128 not individually marked and they were randomly hunted from natural populations, we could not

129 know the mating tactic employed by each male (i.e. harem-defender vs. sneaker). Testes, within

130 the scrotal sac, were cut with a knife and transported to the laboratory in a plastic bag at ambient

131 temperature. Samples were processed between 4 and $8 \mathrm{~h}$ after the death of the animals, a time

132 lapse during which epididymal sperm characteristics do not differ significantly (Soler \& Garde, 
133 2003). However, because we could not establish the exact time of death of each animal, this

134 variable was not include as a covariate in our analyses.

135

136 Testes mass and sperm analyses

137 All of the reagents were purchased from Sigma-Aldrich (Madrid, Spain), unless

138 otherwise indicated. Testes mass was recorded to the nearest $0.01 \mathrm{~g}$ using an electronic balance

139 (EK-400H balance; A\&D Co., Tokyo, Japan) after removing the epididymis and the spermatic

140 cord with a surgical blade. Though the use of relative testes mass is highly preferable for studies

141 such as this, we were unable to quantify male body mass or body size of individual stags due to

142 the working conditions in the field. We therefore chose to use absolute testes mass (i.e. the

143 combined mass of the left and right testis) in the current study. Despite the limitations of such

144 approach, absolute testes mass can still be informative, for example, as a factor that influences

145 variation in sperm size.

146 Sperm morphometry was assessed as previously described (Ros-Santaella, Domínguez-

147 Rebolledo \& Garde, 2014). Briefly, sperm samples were directly recovered from the cauda of

148 both epididymides and fixed in $2 \%$ glutaraldehyde- $0.165 \mathrm{M}$ cacodylate/ $\mathrm{HCl}$ buffer $(\mathrm{pH} 7.3)$.

149 Sperm smears were air-dried for one day, then immersed in the fixative solution for $5 \mathrm{~min}$ and

150 immediately mounted, sealing the edges with DPX mountant for histology. Sperm samples were

151 photographed using a high-resolution DXM1200 camera (Nikon, Tokyo, Japan) under phase-

152 contrast microscopy, using an Eclipse E600 microscope (Nikon, Tokyo, Japan) and a 40X

153 objective (Nikon, Tokyo, Japan). The resolution of the photographs was 3840x3072 pixels (TIFF

154 format). A scale of $10 \mu \mathrm{m}$ (181 pixels) was used for the measurements. The pixel size was 0.055 
$155 \mu \mathrm{m}$ in the horizontal and vertical axes. Sperm lengths were assessed using ImageJ software

156 (National Institutes of Health, USA). We measured the following sperm traits: head width, head

157 length, flagellum length, and midpiece length. From these measurements, we calculated other

158 morphometric parameters such as total sperm length, principal plus terminal piece length, head

159 area, head perimeter, and head ellipticity (head length/head width). The main structures of red

160 deer spermatozoon are shown in Figure 1. A total of 25 spermatozoa per male were measured, as

161 previously described (Malo et al., 2006; Ros-Santaella, Domínguez-Rebolledo \& Garde, 2014).

162 Sperm morphology was evaluated under phase-contrast microscopy using an Eclipse

163 E600 microscope (Nikon, Tokyo, Japan), and a 40X objective (Nikon, Tokyo, Japan). Two

164 hundred spermatozoa per animal were assessed. Normal sperm morphology was calculated as the

165 proportion of spermatozoa without any morphological abnormalities (e.g. pyriform head,

166 detached head, macrocephalic and microcephalic head, bent midpiece, coiled tail, and proximal

167 cytoplasmic droplet). A single trained researcher assessed sperm morphology in order to avoid

168 different evaluation criteria. An example of normal sperm phenotype is shown in Figure 1.

169 Sperm number was calculated by multiplying the epididymal sperm concentration

170 (assessed using a Bürker chamber) by sperm volume. Sperm kinetics was assessed by a CASA

171 (Computer Assisted Sperm Analysis) system. Epididymal sperm were diluted down to 25x10

172 spermatozoa/mL with bovine gamete medium (BGM-3, for medium composition see:

173 Domínguez-Rebolledo et al., 2010) and incubated at $37^{\circ} \mathrm{C}$ in a water bath for $15 \mathrm{~min}$. After

174 dilution and incubation, a sub-sample of $5 \mu \mathrm{L}$ was loaded into a Makler counter chamber

175 (chamber depth: $10 \mu \mathrm{m}$; Sefi-Medical instruments, Haifa, Israel) at $37^{\circ} \mathrm{C}$ for kinetics analysis.

176 The CASA system consisted of an Eclipse 80i triocular optical phase contrast microscope

177 (Nikon, Tokyo, Japan), equipped with a warming stage at $37^{\circ} \mathrm{C}$ and a Basler A302fs digital 
178 camera (Basler Vision Technologies, Ahrensburg, Germany). Videos were captured and

179 analyzed using the Sperm Class Analyzer software (Microptic S.L., Barcelona, Spain). The

180 analysis was carried out using a 10X negative phase-contrast objective (Nikon, Tokyo, Japan). A

181 total of four descriptors of sperm motility were recorded analyzing a minimum of 250 sperm per

182 sample: average path velocity (VAP, $\mu \mathrm{m} / \mathrm{s}$ ), curvilinear velocity (VCL, $\mu \mathrm{m} / \mathrm{s}$ ), straight linear

183 velocity (VSL, $\mu \mathrm{m} / \mathrm{s})$, and progressive sperm motility (\%). Progressive sperm motility was

184 defined as the sperm that swim forward in a straight line (i.e. straightness $\geq 80 \%$ ). Thus,

185 spermatozoa with an abnormal swimming path (e.g. tight circles) were not included in the

186 proportion of progressive sperm motility. Average path velocity (VAP), VCL, and VSL are

187 strongly related to fertility in this species (Malo et al. 2005b). The standard parameter settings

188 were as follows: 25 frames/s; 20 to $60 \mu \mathrm{m}^{2}$ for the head area; and a VCL $>10 \mu \mathrm{m} / \mathrm{s}$ to classify a

189 spermatozoon as motile, as previously described (Domínguez-Rebolledo et al., 2011).

190 Additionally to these cut-off settings, each recorded video was visually checked in order to

191 ensure that neither debris nor dead-spermatozoa were included as motile sperm.

192

193 Statistical analysis

194 All statistical analyses were performed using the SPSS 20.0 statistical software package

195 (IBM Inc, Chicago, IL, USA). The Kolmogorov-Smirnov and Levene's tests were used to check

196 data normality and homogeneity of variance, respectively. The intramale coefficient of variation

$197(\mathrm{CV}=$ standard deviation/mean $\mathrm{x}$ 100) was calculated using the measurements of each

198 spermatozoon, for each male. We also calculated the intermale CV from the average of each

199 morphometric parameter. To check for differences between the intramale CV of the sperm head 
200 and flagellum components, we used paired samples Student's t-test. For this analysis we used the

201 average intramale CV of the sperm head (length, width, area, ellipticity, and perimeter) and

202 flagellum parameters (flagellum, midpiece, and principal plus terminal piece lengths) for each

203 male. Absolute testes mass was $\log _{10}$ transformed due to the high variability found between

204 males. Principal component analysis (PCA) was performed to obtain a single parameter

205 describing sperm velocity. Average path velocity (VAP) was significantly correlated with VSL

206 and VCL $(\mathrm{r}=0.86 ; P<0.001$ and $\mathrm{r}=0.54 ; P=0.024$, respectively), whereas, VCL and VSL were

207 positively associated, but not significantly $(\mathrm{r}=0.10 ; P=0.691)$. Principal components with an

208 eigenvalue $>1$ were retained. Pearson's correlation (two-tailed) test was used to assess the

209 relationships between the intramale CV for the sperm size parameters with testes mass and the

210 different sperm traits evaluated (i.e. sperm velocity, progressive sperm motility, normal sperm

211 morphology, and sperm number).

212

213 Results

214 CV in sperm size and its relationships with sperm kinetics and normal sperm morphology

215 The descriptive statistics of sperm parameters are shown in Table 1. The mean value of

216 the intramale $\mathrm{CV}$ of the total sperm length was low (1.31\%). Similarly, mean values of the

217 remaining intramale $\mathrm{CV}$ of the sperm morphometry parameters were generally low to moderate,

218 ranging from $1.33 \%$ to $4.56 \%$ (Table 1; Figure 2A). Moreover, the intramale CV of the flagellum

219 measures was significantly lower than that found in the sperm head measures $(\mathrm{t}=17.53 ; \mathrm{df}=16$;

$220 P<0.001$; Figure $2 \mathrm{~B}$ ). The intermale $\mathrm{CV}$ of the sperm head and the flagellum parameters were

221 also low to moderate, ranging from $1.56 \%$ to $3.62 \%$ (Figure $2 \mathrm{C}$ ). Principal component analysis 
222 (PCA) rendered only one component with an eigenvalue $>1$ that explained $68.77 \%$ of the

223 variance in the sperm velocity variables (Table 2). All sperm velocity variables (VAP, VCL, and

224 VSL) were positively and significantly related to PC1 scores $(P<0.05$; Table 2$)$. The eigenvalues

225 and the variance explained by the other components are also shown in Table 2. Sperm velocity

226 showed negative relationships with the intramale $\mathrm{CV}$ of the total sperm length $(\mathrm{r}=-0.54$;

$227 P=0.025$; Figure 3A; Table S1), head ellipticity $(\mathrm{r}=-0.49 ; P=0.047$; Figure 3B; Table S1),

228 flagellum length $(\mathrm{r}=-0.61 ; P=0.010$; Figure $3 \mathrm{C}$; Table $\mathrm{S} 1)$, and principal plus terminal piece

229 length ( $\mathrm{r}=-0.61 ; P=0.009$; Figure 3D; Table S1). The percentage of sperm with progressive

230 motility showed negative relationships with the intramale CV of the total sperm length $(\mathrm{r}=-0.49$;

$231 P=0.045$; Figure 4A; Table S1), flagellum length $(\mathrm{r}=-0.57 ; P=0.016$; Figure 4B; Table $\mathrm{S} 1)$,

232 principal plus terminal piece length $(\mathrm{r}=-0.63 ; P=0.007$; Figure $4 \mathrm{C}$; Table $\mathrm{S} 1)$, and head ellipticity

$233(\mathrm{r}=-0.63 ; P=0.007$; Figure 4D; Table S1). Moreover, the intramale CV of the sperm head area

234 and perimeter were negatively related to the percentage of normal sperm morphology $(\mathrm{r}=-0.54$;

$235 P=0.027$ and $\mathrm{r}=-0.53 ; P=0.029$, respectively; Table $\mathrm{S} 1)$. The Pearson's correlations of the

236 intramale CV in the sperm morphometry parameters with sperm kinetics and normal sperm

237 morphology are shown in Table S1.

238

239 Absolute testes mass, CV in sperm size, and sperm number

240 As expected, the absolute testes mass exhibited high variability between males

$241(\mathrm{CV}=43.38 \%)$ ranging from $47.49 \mathrm{~g}$ to $165.51 \mathrm{~g}$ with an average mass of $88.55 \pm 38.42 \mathrm{~g}$

242 (Mean \pm SD). We found significant and negative relationships between absolute testes mass and

243 the intramale $\mathrm{CV}$ of total sperm length $(\mathrm{r}=-0.58 ; P=0.016$; Figure $5 \mathrm{~A}$; Table $\mathrm{S} 1)$, sperm head 
244 width $(\mathrm{r}=-0.70 ; P=0.002$; Figure 5B; Table $\mathrm{S} 1)$, and midpiece length $(\mathrm{r}=-0.49 ; P=0.046$; Figure

245 5C; Table S1). The same relationship trends were also found for the remaining intramale CV of

246 the sperm morphometry parameters, although they were not significant $(P>0.05$; Table S1). We

247 did not find any significant relationship between the intramale CV in sperm size and sperm

248 number $(P>0.05$; Table $\mathrm{S} 1)$. Finally, we found a positive relationship between absolute testes

249 mass and sperm number, but it was not significant $(\mathrm{r}=0.35 ; P=0.371)$.

\section{Discussion}

In the present work we provide empirical evidence that intramale variation in sperm size

253 is significantly associated with sperm velocity in a polygynous mammal, the red deer. Sperm

254 with low variation in their size swim faster. To our knowledge, this relationship between sperm

255 size variation and sperm velocity has never been described before in mammals and can

256 significantly contribute to the understanding of related patterns and processes observed across

257 animal populations and species (Immler, Calhim \& Birkhead, 2008; Laskemoen et al., 2013). In

258 addition, intramale variation in sperm head size is negatively related to normal sperm

259 morphology. Highlighting the significance of our findings, previous studies reported that sperm

260 velocity and normal morphology are related to male fertility and the sex ratio at the time of birth

261 in red deer (Malo et al., 2005b; Gomendio et al., 2006), suggesting that post-copulatory sexual

262 selection reduces variation in sperm size. Moreover, absolute testes mass was negatively related

263 to intramale variation in sperm size (i.e. sperm length, head width, and midpiece length), though

264 we suggest this result is treated with caution as both relative testes mass and male mating tactic

265 (i.e. harem defender versus sneaker) could influence this relationship. This trend of relationship 
266 between testes mass and intramale $\mathrm{CV}$ in sperm size is linked to the level of sperm competition

267 and extrapair paternity among related taxa (Kleven et al., 2008; Šandera, Albrecht \& Stopka,

268 2013). Our results tentatively suggest that large testes in red deer lead to sperm closer to the

269 putative optimal size, which potentially enhances sperm competitiveness.

270

The consequences of having a low variation in sperm size still remain poorly

271 investigated, and might be expected to improve some sperm traits related to fertilization success.

272 As a generalization of our study, intramale and intermale variations in sperm size were low both

273 for the head and the flagellum structures, suggesting that in red deer stabilizing selection might

274 act on sperm to reduce their variation in size. Moreover, we found that the variation in sperm

275 measures was higher for those of the sperm head than for the sperm flagellum, as previously

276 reported in murine rodents (Varea-Sánchez et al., 2014). Such a result may be linked to the size

277 difference between $\mathrm{X}$ and $\mathrm{Y}$ chromosome bearing spermatozoa found in humans ( $\mathrm{X}$ is larger than

278 Y; Cui \& Matthews, 1993), as these size differences are more significant for the sperm head than

279 for the flagellum components (Cui \& Matthews, 1993; Cui, 1997). Recently, Mossman et al.

280 (2013) reported that the variation in the length of sperm components in humans undergoing

281 treatment for infertility correlated with the proportion of motile sperm, but the authors did not

282 find any association with sperm velocity parameters. However, in two closely related species of

283 lizards, the relationships between the intramale variation in sperm size and sperm velocity

284 showed contradictory results (Blengini et al., 2014). In agreement with Mossman et al. (2013),

285 we found that the intramale variation in sperm size is negatively related to the percentage of

286 sperm with progressive motility. Further, in our study, we found a strong negative relationship

287 between the intramale variation in sperm size and sperm velocity, which in turn is highly related

288 to male fertility in red deer (Malo et al., 2005b). 
290 showed a strong relationship with sperm velocity. On the contrary, we did not find any

291 significant relationship between sperm velocity and the intramale CV of the sperm midpiece

292 length, probably because glycolysis, which appears to be carried out along the length of the

293 principal piece, is the most important source of ATP for the tail, instead of oxidative

294 phosphorylation in the midpiece (Turner, 2006). Further, in red deer, the length of the principal

295 plus the terminal piece in relation to the rest of the flagellum as well as head ellipticity play an

296 important role in determining sperm velocity (Malo et al., 2006). For this reason, ejaculates with

297 more uniform size of these sperm traits may be more successful at achieving fertilizations under

298 competitive mating scenarios. Moreover, we found that the intramale variation in the sperm head

299 size (area and perimeter) is negatively correlated with the percentage of normal sperm

300 morphology, which in turn plays a key role in male fertility as well as in the offspring's sex ratio

301 in red deer (Malo et al., 2005b; Gomendio et al., 2006). In the present study, a reduced intramale

302 variation in sperm size was related to high sperm velocity and normal morphology, which might

303 be indicative of an efficient spermatogenesis. On the other hand, the factors and mechanisms

304 involved in the production of sperm with low variation in their size still remain unknown and

305 deserve further investigation. It is well known that Sertoli cells are involved in several important

306 processes, such as the elongation of spermatids and the formation of sperm tails (Griswold,

307 2004), among others. Because Sertoli cell number covaries with testis mass and sperm function

308 in red deer (Pintus, Ros-Santaella \& Garde, 2015), we hypothesize that Sertoli cells can also play

309 a role in determining the intramale variation in sperm size, in agreement with the hypothesis

310 given by Mossman et al. (2013). A high Sertoli cell number or functionality may lead to better-

311 manufactured sperm, thus enhancing sperm function. 
312 We found high variability in absolute testes mass among red deer males as previously

313 described (Martínez-Pastor et al., 2005; Pintus, Ros-Santaella \& Garde, 2015). Studies in natural

314 populations of ungulates, such as red deer and Soay sheep, have shown that testes size (both

315 relative and absolute) is positively correlated with antler and horn size (Preston et al., 2003;

316 Malo et al., 2005a), copula rates, and siring success (Preston et al., 2003). Our results show that

317 large absolute testes mass is also associated with low sperm size variability. Furthermore, we

318 found a positive relationship between absolute testes mass and sperm number, but it was not

319 significant. We speculate that these results may reflect an increase in testes mass in order to

320 produce more size-uniform sperm as occurs at intraspecific level (birds: Immler, Calhim \&

321 Birkhead, 2008; mammals: Šandera, Albrecht \& Stopka, 2013). This idea is somewhat supported

322 by the fact that, across species, both sperm morphology and sperm number are influenced by

323 testicular architecture (e.g. relative proportion of spermatogenic tissue and size of the tubule

324 lumen; Lupold et al. 2009b; Rowe \& Pruett-Jones 2011) and the efficiency of spermatogenesis

325 (e.g. shorter duration of the cycle of the seminiferous epithelium; Ramm \& Stockley 2010).

In conclusion, in the present work, we provide empirical evidence that low variation in

327 sperm size is associated with high sperm velocity and normal morphology. Taking into account

328 that these last two sperm traits are good predictors of male fertility in red deer (Malo et al.,

329 2005b), our findings suggest that sperm size variation is under strong post-copulatory sexual

330 selection in this species. Furthermore, we found that absolute testes mass is negatively associated

331 with intramale variation in sperm size. However, while our results are robust, they need to be

332 considered with some caution because of the sample size used. Moreover, male mating tactics

333 and relative testes mass were unknown and could have an effect on the main sperm traits

334 evaluated. With the findings of the present work, we can add new information to the general 
335 scheme about the male traits that potentially enhance sperm competitiveness, which in turn

336 determine male fertility in red deer (Figure 6). Our next step is to examine the possible

337 relationships between sperm phenotype, testicular architecture, and spermatogenic features, as

338 well as whether intramale variation in sperm size is a predictor of male fertilization ability. Our

339 results highlight the importance of assessing intramale variation in sperm size for an enhanced

340 understanding of post-copulatory sexual selection mechanisms.

\section{Acknowledgments}

The assistance provided by Alvaro Domínguez-Rebolledo, Alfonso Bisbal, Enrique del

344 Olmo, Mari Cruz Sotos, and Zandra Maulen is gratefully acknowledged. Authors acknowledge

345 Gregorio Moreno-Rueda for his insightful comments and Christina Baker for English language

346 editing. Landowners, managers, and rangers are acknowledged for facilitating access to samples.

347

348 References

349 Birkhead TR, AP Møller. 1998. Sperm competition and sexual selection. London, UK: Academic $350 \quad$ Press.

351 Birkhead TR, Immler S. 2007. Making sperm: design, quality control and sperm competition.

352 Society of Reproduction and Fertility supplement 65:175-181. 
353 Blengini CS, Sergio N, Gabriela C, Giojalas LC, Margarita C. 2014. Variability in sperm form

354 and function in the context of sperm competition risk in two Tupinambis lizards. Ecology

355 and Evolution 4:4080-4092.

356 Calhim S, Double MC, Margraf N, Birkhead TR, Cockburn A. 2011. Maintenance of sperm

357 variation in a highly promiscuous wild bird. PloS One 6:e28809.

358 Clutton-Brock TH, Guinness FE, Albon SD. 1982. Red Deer: Behaviour and ecology of two

359 sexes. Chicago, US: Chicago University Press.

360 Cramer ERA, Laskemoen T, Stensrud E, Rowe M, Haas F, Lifjeld JT, Sætre G, Johnsen A.

361 2014. Morphology-function relationships and repeatability in the sperm of passer sparrows.

$362 \quad$ Journal of Morphology 8:1-8.

363 Cui KH, Matthews CD. 1993. X larger than Y. Nature. 366:117-118.

364 Cui KH. 1997. Size differences between human X and Y spermatozoa and prefertilization 365 diagnosis. Molecular Human Reproduction 3:61-67.

366 Domínguez-Rebolledo AE, Fernández-Santos MR, Bisbal A, Ros-Santaella JL, Ramón M,

367 Carmona M, Martínez-Pastor F, Garde JJ. 2010. Improving the effect of incubation and

368 oxidative stress on thawed spermatozoa from red deer by using different antioxidant

369 treatments. Reproduction, Fertility, and Development 22:856-70.

370 Domínguez-Rebolledo AE, Martínez-Pastor F, Bisbal AF, Ros-Santaella JL, García-Álvarez O,

371 Maroto-Morales A, Soler AJ, Garde JJ, Fernández-Santos MR. 2011. Response of thawed 
epididymal red deer spermatozoa to increasing concentrations of hydrogen peroxide, and importance of individual male variability. Reproduction in Domestic Animals 46:393-403.

374 Firman RC, Simmons LW. 2010. Sperm midpiece length predicts sperm swimming velocity in 375 house mice. Biology Letters 6:513-516.

376

377

378

379

380

381

382

383

384

385

386

387

388

389

390

Fitzpatrick JL, Baer B. 2011. Polyandry reduces sperm length variation in social insects. Evolution 65:3006-3012.

Fitzpatrick JL, Lüpold S. 2014. Sexual selection and the evolution of sperm quality. Molecular Human Reproduction 0:1-10.

García-González F, Simmons LW. 2005. Sperm viability matters in insect sperm competition. Current Biology 15:271-275.

Gomendio M, Malo AF, Soler AJ, Fernández-Santos MR, Esteso MC, García AJ, Roldan ERS, Garde J. 2006. Male fertility and sex ratio at birth in red deer. Science 314:1445-1447.

Gómez Montoto L, Magaña C, Tourmente M, Martín-Coello J, Crespo C, Luque-Larena JJ, Gomendio M, Roldan ERS. 2011. Sperm competition, sperm numbers and sperm quality in muroid rodents. PloS One 6:e18173.

Griswold MD. 2004. Perspective on the function of Sertoli cells. In: Skinner MK, Griswold MD, ed. Sertoli cell biology. San Diego, US: Elsevier Academic Press, 15-18.

Guinness F, Lincoln GA, Short RV. 1971. Reproductive cycle of female red deer, Cervus elaphus L. Journal of Reproduction and Fertility 27:427-438. 
391 Helfenstein F, Podevin M, Richner H. 2009. Sperm morphology, swimming velocity, and 392 longevity in the house sparrow Passer domesticus. Behavioral Ecology and Sociobiology $393 \quad 64: 557-565$.

394 Van der Horst G, Maree L. 2014. Sperm form and function in the absence of sperm competition. 395 Molecular Reproduction and Development 81:204-216.

396 Humphries S, Evans JP, Simmons LW. 2008. Sperm competition: linking form to function. BMC 397 Evolutionary Biology 8:319.

398 Immler S. 2008. Sperm competition and sperm cooperation: the potential role of diploid and 399 haploid expression. Reproduction 135:275-283.

400 Immler S, Calhim S, Birkhead TR. 2008. Increased postcopulatory sexual selection reduces the 401 intramale variation in sperm design. Evolution 62:1538-1543.

402 Jarnemo A. 2011. Male red deer (Cervus elaphus) dispersal during the breeding season. Journal 403 of Ethology 29:329-336.

404 Kelly CD. 2008. Sperm investment in relation to weapon size in a male trimorphic insect?. 405 Behavioral Ecology 19:1018-1024.

406 Kleven O, Laskemoen T, Fossøy F, Robertson RJ, Lifjeld JT. 2008. Intraspecific variation in 407 sperm length is negatively related to sperm competition in passerine birds. Evolution $408 \quad 62: 494-499$. 
409 Kleven O, Fossøy F, Laskemoen T, Robertson RJ, Rudolfsen G, Lifjeld JT. 2009. Comparative

410 evidence for the evolution of sperm swimming speed by sperm competition and female

411 sperm storage duration in passerine birds. Evolution 63:2466-2473.

412 Laskemoen T, Albrecht T, Bonisoli-Alquati A, Cepak J, de Lope F, Hermosell IG, Johannessen

413 LE, Kleven O, Marzal A, Mousseau TA, Møller AP, Robertson RJ, Rudolfsen G, Saino N,

414 Vortman Y, Lifjeld JT. 2013. Variation in sperm morphometry and sperm competition

415 among barn swallow (Hirundo rustica) populations. Behavioral Ecology and Sociobiology

$416 \quad 67: 301-309$.

417 Liao WB, Mi ZP, Li CL, Wei SC, Wu H. 2013. Sperm traits in relation to male amplexus

418 position in the Omei treefrog Rhacophorus omeimontis, a species with group spawning. The

419 Herpetological Journal 23:17-21.

420 Lüpold S, Calhim S, Immler S, Birkhead TR. 2009a. Sperm morphology and sperm velocity in 421 passerine birds. Proceedings of the Royal Society B 276:1175-1181.

422 Lüpold S, Linz GM, Rivers JW, Westneat DF, Birkhead TR. 2009b. Sperm competition selects

423 beyond relative testes size in birds. Evolution 63:391-402.

424 Lüpold S. 2013. Ejaculate quality and constraints in relation to sperm competition levels among 425 eutherian mammals. Evolution 67:3052-3060.

426 Malo AF, Roldan ERS, Garde J, Soler AJ, Gomendio M. 2005a. Antlers honestly advertise 427 sperm production and quality. Proceedings of the Royal Society B 272:149-157. 
428 Malo AF, Garde JJ, Soler AJ, García AJ, Gomendio M, Roldan ERS. 2005b. Male fertility in

429 natural populations of red deer is determined by sperm velocity and the proportion of 430 normal spermatozoa. Biology of Reproduction 72:822-829.

431 Malo AF, Gomendio M, Garde J, Lang-Lenton B, Soler AJ, Roldan ERS. 2006. Sperm design 432 and sperm function. Biology Letters 2:246-249.

433 Martínez-Pastor F, Guerra C, Kaabi M, Garcia-Macias V, de Paz P, Alvarez M, Herraez P, Anel

434 L. 2005. Season effect on genitalia and epididymal sperm from Iberian red deer, roe deer 435 and Cantabrian chamois. Theriogenology 63:1857-1875.

436

438

439

440

441

442

443

444

445

446

Merilä J, Sheldon BC. 1999. Testis size variation in the greenfinch Carduelis chloris: Relevance for some recent models of sexual selection. Behavioral Ecology and Sociobiology 45:115123.

Mossman J, Pearson JT, Moore HD, Pacey A. 2013. Variation in mean human sperm length is linked with semen characteristics. Human Reproduction 28:22-32.

Parker GA. 1998. Sperm competition and the evolution of ejaculates: towards a theory base. In: Birkhead TR, Møller AP, ed. Sperm competition and sexual selection. London, UK: Academic Press, 3-54.

Pemberton JM, Albon SD, Guinness FE, Clutton-brock TH, Dover G a. 1992. Behavioral estimates of male mating success tested by DNA fingerprinting in a polygynous mammal. Behavioral Ecology 3:66-75. 
447 Pérez-González J, Carranza J. 2011. Female aggregation interacts with population structure to

448 influence the degree of polygyny in red deer. Animal Behaviour 82:957-970.

449 Pintus E, Ros-Santaella JL, Garde JJ. 2015. Beyond testis size: links between spermatogenesis

450 and sperm traits in a seasonal breeding mammal. PloS One 10:e0139240.

451 Pitnick S, Hosken DJ, Birkhead TR. 2009. Sperm morphological diversity. In: Birkhead TR, 452 Hosken DJ, Pitnick S, ed. Sperm biology: an evolutionary perspective. Oxford, UK: 453 Academic Press, 69-149.

454 Pizzari T, Parker GA. 2009. Sperm competition and sperm phenotype. In: Birkhead TR, Hosken 455 DJ, Pitnick S, ed. Sperm biology: an evolutionary perspective. Oxford, UK: Academic 456 Press, 207-245.

457 Preston BT, Stevenson IR, Pemberton JM, Coltman DW, Wilson K. 2003. Overt and covert 458 competition in a promiscuous mammal: the importance of weaponry and testes size to male 459 reproductive success. Proceedings of the Royal Society B 270:633-40.

460 Ramm SA, Stockley P. 2010. Sperm competition and sperm length influence the rate of 461 mammalian spermatogenesis. Biology Letters 6(2):219-221.

462 Ramón M, Soler AJ, Ortiz JA, García-Alvarez O, Maroto-Morales A, Roldan ERS, Garde JJ.

463 2013. Sperm population structure and male fertility: an intraspecific study of sperm design 464 and velocity in red deer. Biology of Reproduction 89:110.

465 Ros-Santaella JL, Domínguez-Rebolledo AE, Garde JJ. 2014. Sperm flagellum volume 466 determines freezability in red deer spermatozoa. PloS One 9:e112382. 
467 Rowe M, Pruett-Jones S. 2011. Sperm competition selects for sperm quantity and quality in the 468 australian Maluridae. PloS One 6(1): e15720.

469 Šandera M, Albrecht T, Stopka P. 2013. Variation in apical hook length reflects the intensity of $470 \quad$ sperm competition in murine rodents. PloS One 8:e68427.

471

472

473

474

475

476

477

478

479

480

481

482

483

484

485

486

Schulte-Hostedde AI, Millar JS. 2004. Intraspecific variation of testis size and sperm length in the yellow-pine chipmunk (Tamias amoenus): implications for sperm competition and reproductive success. Behavioral Ecology and Sociobiology 55:272-277.

Simmons LW, Fitzpatrick JL. 2012. Sperm wars and the evolution of male fertility. Reproduction 144:519-534.

Simmons LW, Emlen DJ. 2006. Evolutionary trade-off between weapons and testes. Proceedings of the National Academy of Sciences 103:16346-16351.

Simpson JL, Humphries S, Evans JP, Simmons LW, Fitzpatrick JL. 2014. Relationships between sperm length and speed differ among three internally and three externally fertilizing species. Evolution 68:92-104.

Soler AJ, Garde JJ. 2003. Relationship between the characteristics of epididymal red deer spermatozoa and penetrability into zona-free hamster ova. Journal of Andrology 24:393400.

Stopher K V., Nussey DH, Clutton-Brock TH, Guinness F, Morris a., Pemberton JM. 2011. The red deer rut revisited: female excursions but no evidence females move to mate with preferred males. Behavioral Ecology 22:808-818. 
487 Turner RM. 2006. Moving to the beat: a review of mammalian sperm motility regulation.

488 Reproduction, Fertility, and Development 18:25-38.

489 Varea-Sánchez M, Gómez Montoto L, Tourmente M, Roldan ERS. 2014. Postcopulatory sexual

490 selection results in spermatozoa with more uniform head and flagellum sizes in rodents.

$491 \quad$ PloS One 9:e108148. 
1

Figure 1. The main structures of red deer spermatozoon.

The photograph was taken under phase contrast microscopy (40X objective). Scale bar, 10 $\mu \mathrm{m}$.

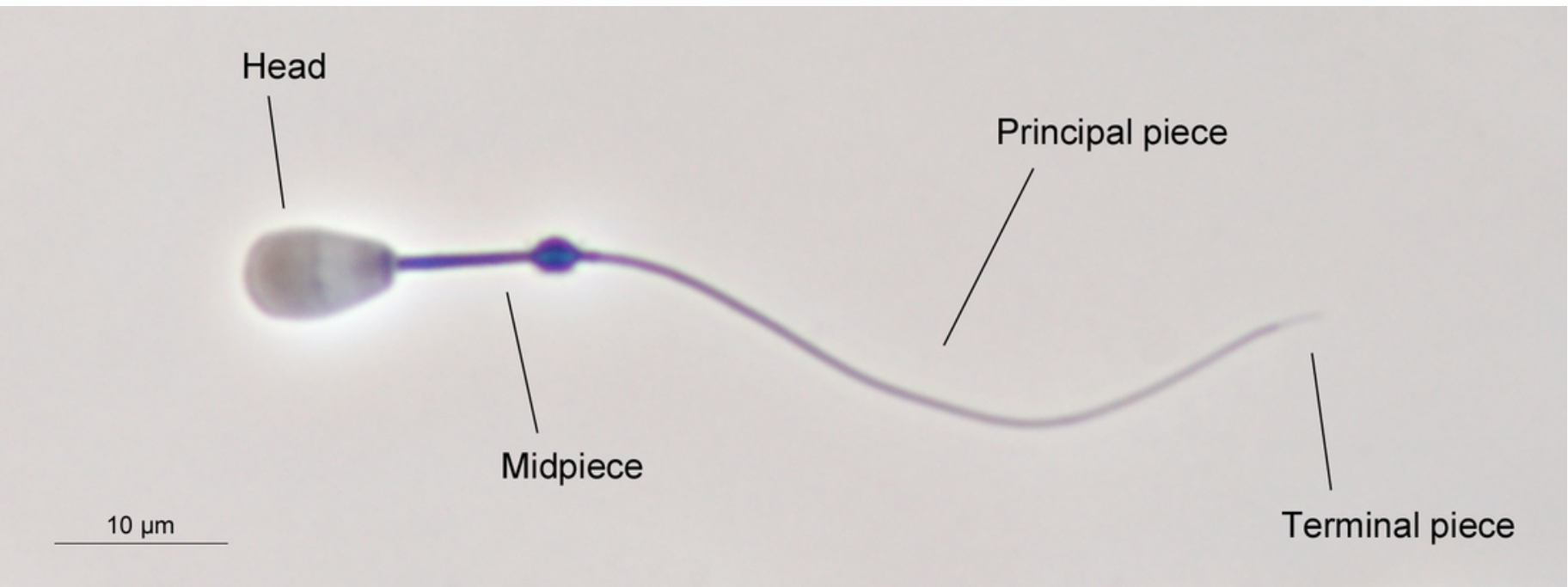


2

Figure 2. Coefficients of variation in sperm morphometry parameters.

A) Intramale coefficient of variation of the sperm morphometry parameters in red deer stags $(\mathrm{N}=17)$; B) Differences between the intramale coefficient of variation of the sperm head and flagellum components. Different letters differ significantly $(P<0.001)$; $\mathbf{C})$ Intermale coefficient of variation in sperm size. $C V=$ coefficient of variation; $T S L=$ total sperm length; $F L=$ flagellum length; $P P L=$ principal plus terminal piece length; $H P=$ head perimeter; $M P L=$ midpiece length; $H L=$ head length; $H W=$ head width; $H L / H W=$ head ellipticity; $H A=$ head area. 

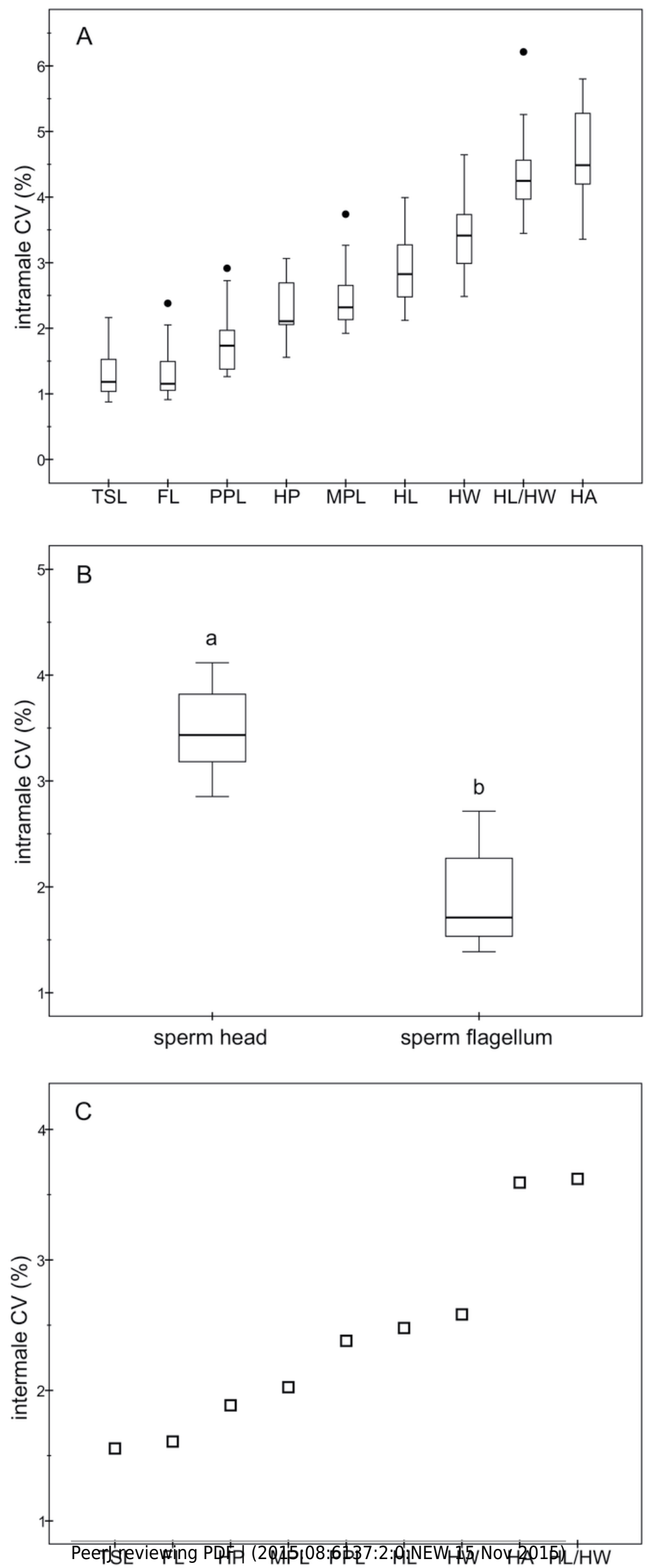
3

Figure 3. Relationships between sperm velocity and the intramale coefficient of variation in sperm size.

Relationships between sperm velocity and the intramale $\mathrm{CV}$ of: $\mathbf{A}$ ) total sperm length: $\mathrm{r}=-$ $0.54 ; P=0.025$; B) head ellipticity: $r=-0.49 ; P=0.047 ; C$ ) flagellum length: $r=-0.61 ; P=0.010$;

D) principal plus terminal piece length: $r=-0.61 ; P=0.009$. $C V=$ coefficient of variation; $\mathrm{PC} 1=$ principal component 1 .
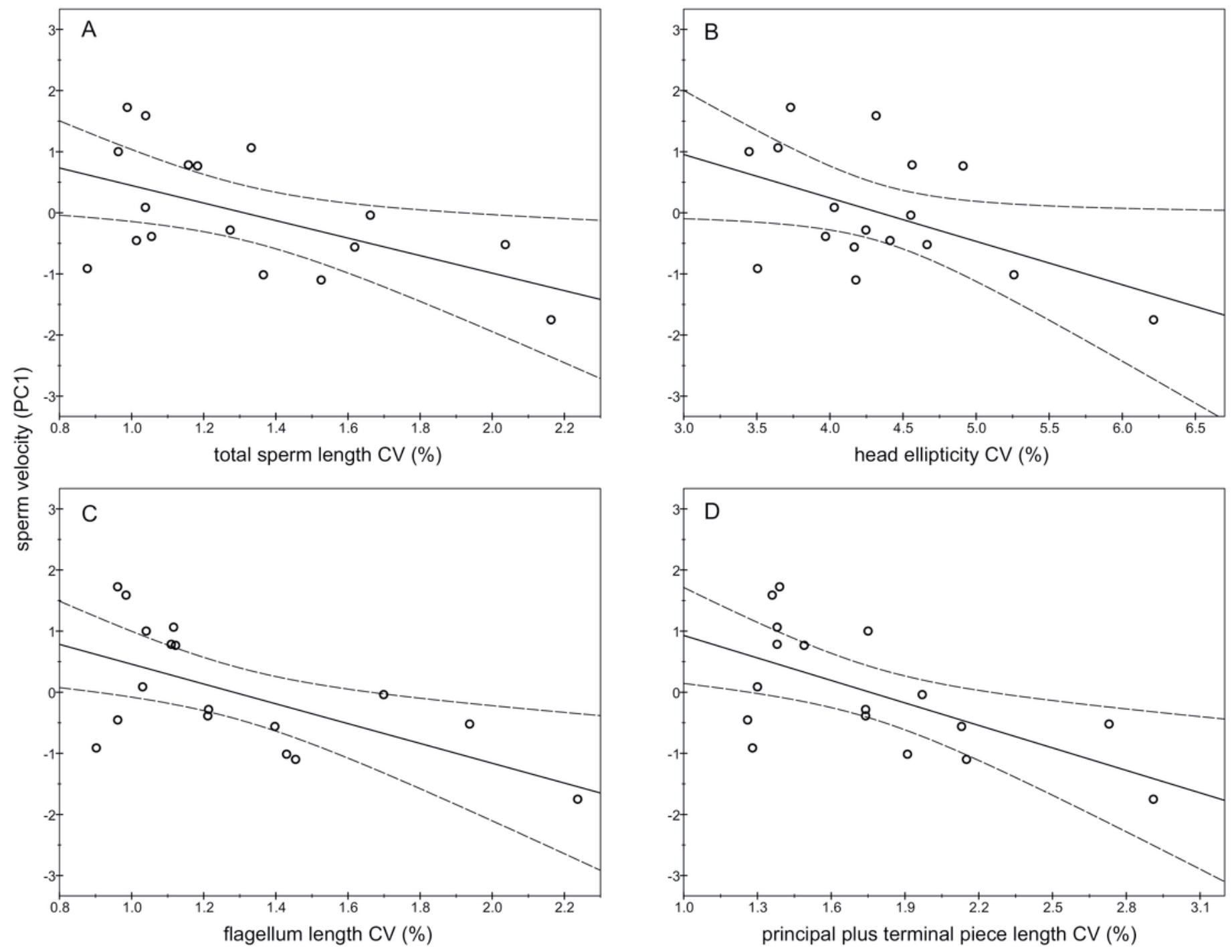
4

Figure 4. Relationships between the percentage of sperm with progressive motility and the intramale coefficient of variation in sperm size.

Relationships between sperm progressive motility and the intramale CV of: $\mathbf{A})$ total sperm length: $r=-0.49 ; P=0.045 ; \mathbf{B})$ flagellum length: $r=-0.57 ; P=0.016 ; \mathbf{C}$ ) principal plus terminal piece length: $r=-0.63 ; P=0.007 ; D)$ head ellipticity: $r=-0.63 ; P=0.007 . C V=$ coefficient of variation.
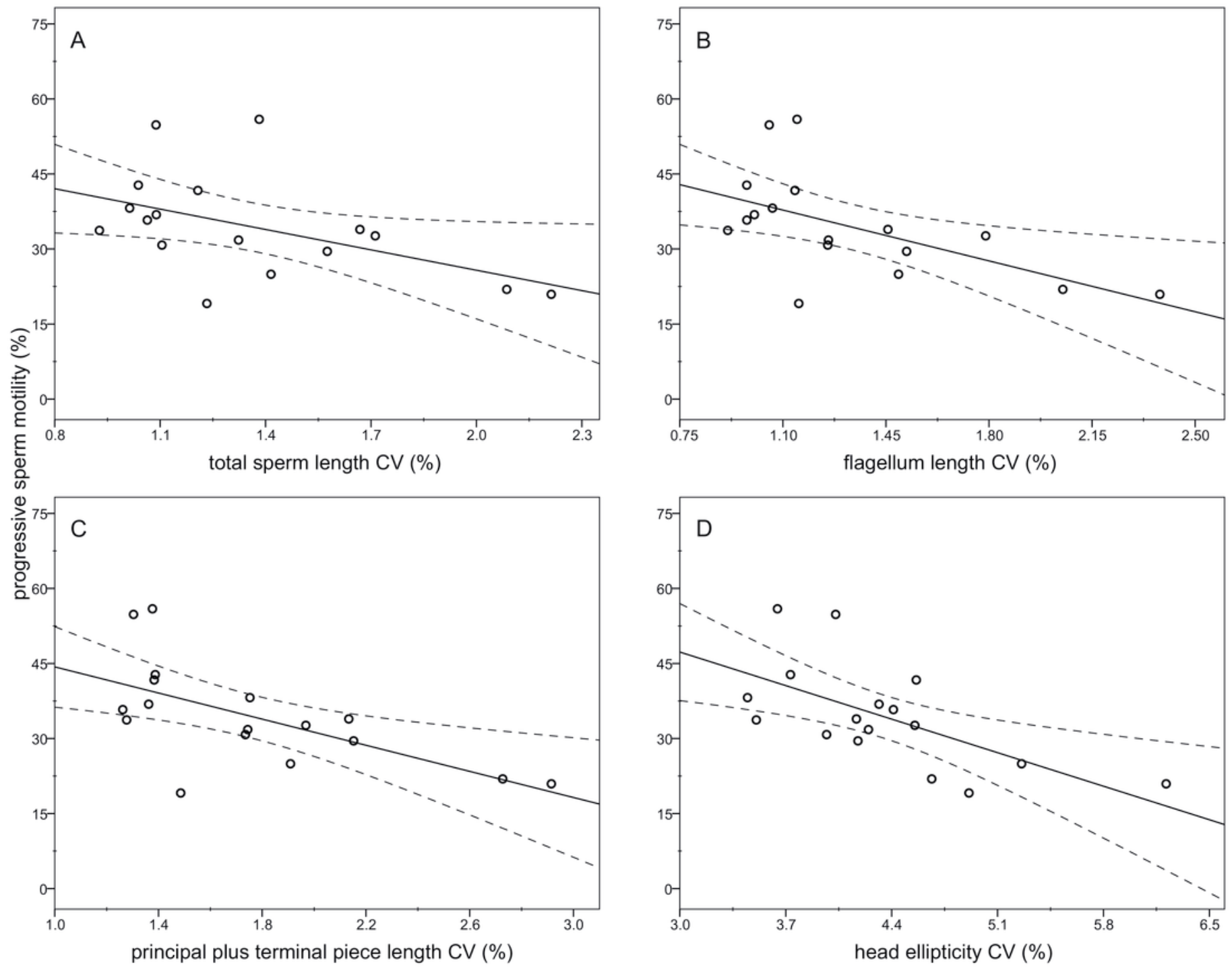


\section{5}

Figure 5. Relationships between absolute testes mass $\left(\log _{10}\right)$ and the intramale coefficient of variation in sperm size.

Relationships between absolute testes mass and intramale $\mathrm{CV}$ of: $\mathbf{A})$ total sperm length: $\mathrm{r}=-$ $0.58 ; P=0.016$; B) head width: $r=-0.70 ; P=0.002 ; C)$ midpiece length: $r=-0.49 ; P=0.046$. $\mathrm{CV}=$ coefficient of variation. 

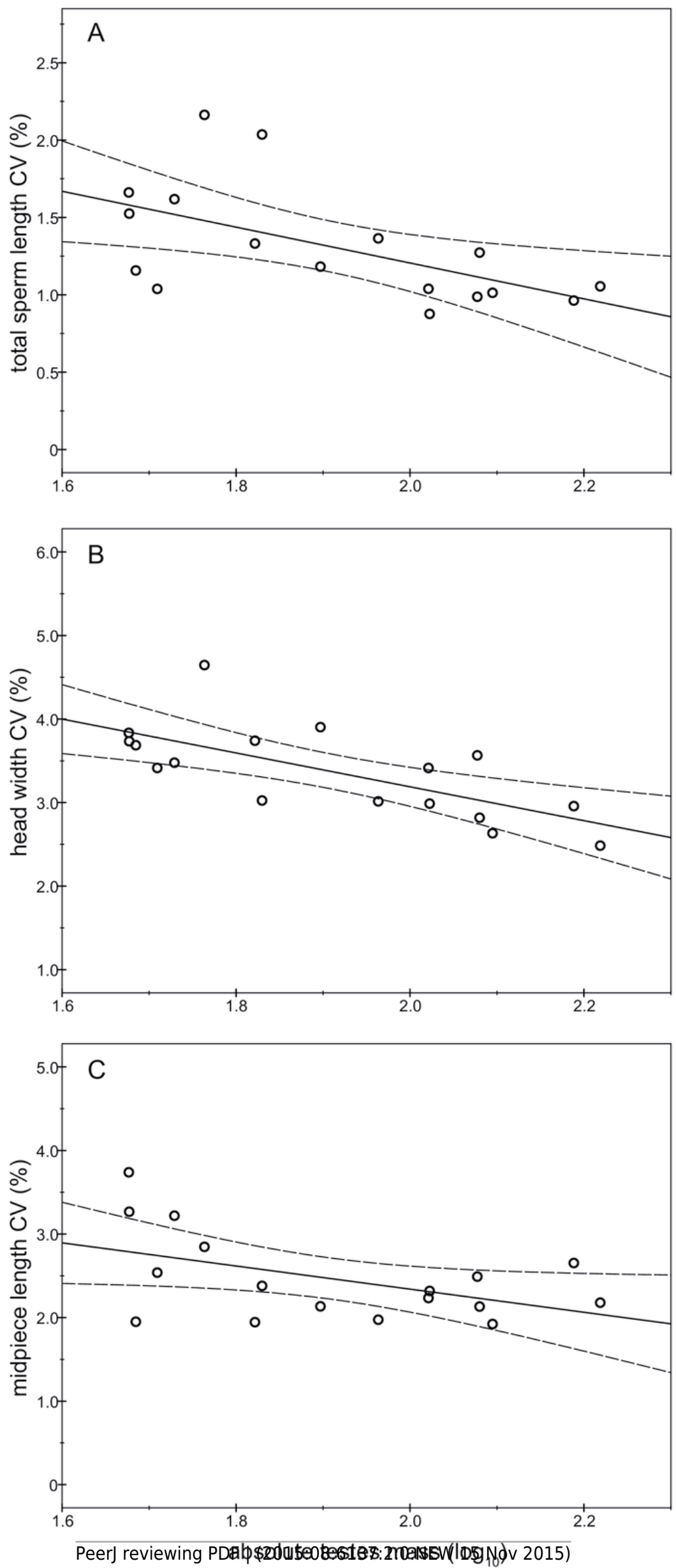
6

Figure 6. General scheme of male traits related to sperm competitiveness and fertility in red deer.

White arrows indicate positive relationships. Black arrows indicate negative relationships. 1)

Malo et al. 2005a; 2) Present work; 3) Malo et al. 2005b. *= In the present work we have used absolute testes mass instead of relative testes mass. ?= Needs to be evaluated.

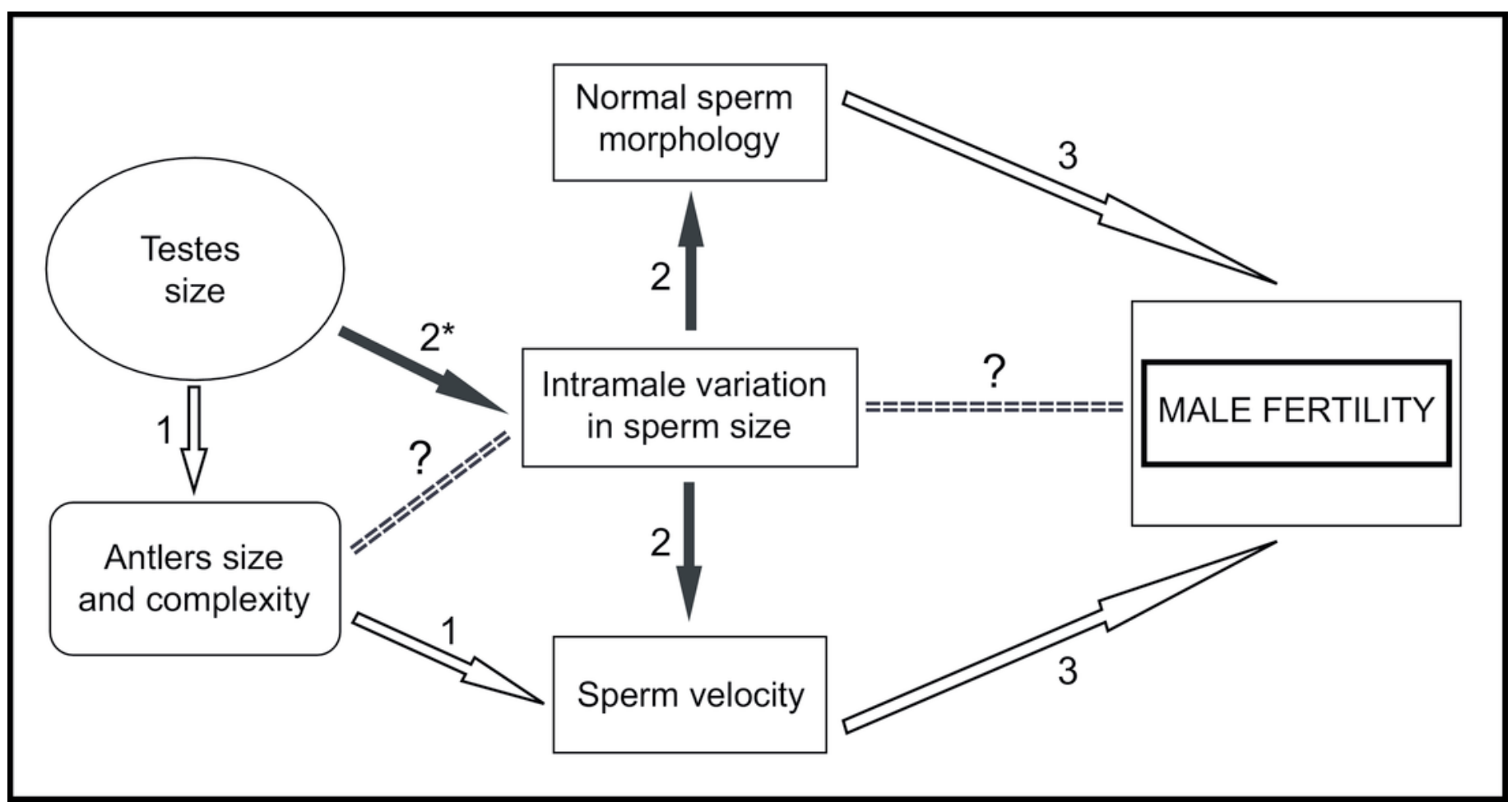




\section{Table $\mathbf{1}$ (on next page)}

Sperm parameters and the intramale coefficient of variation in sperm morphometry in red deer $(\mathrm{N}=17)$.

$\mathrm{VAP}=$ average path velocity; $\mathrm{VCL}=$ curvilinear velocity; $\mathrm{VSL}=$ straight linear velocity; $\mathrm{SD}=$ standard deviation; $\mathrm{CV}=$ coefficient of variation. 
3 Table 1. Sperm parameters and the intramale coefficient of variation in sperm morphometry

$4 \quad$ of red deer $(\mathrm{N}=17)$.

\begin{tabular}{lll}
\hline Assessed parameters & Mean \pm SD & Range (min-max) \\
\hline
\end{tabular}

Sperm kinetics, morphology, and sperm number

$\operatorname{VAP}(\mu \mathrm{m} / \mathrm{s})$

$\operatorname{VCL}(\mu \mathrm{m} / \mathrm{s})$

$\operatorname{VSL}(\mu \mathrm{m} / \mathrm{s})$

Progressive motility (\%)

Normal morphology (\%)

Sperm number $\left(10^{6}\right)$

$\begin{array}{cc}104.24 \pm 9.95 & 86.73-119.71 \\ 154.41 \pm 14.60 & 129.19-179.14 \\ 73.03 \pm 11.81 & 53.45-93.53 \\ 34.43 \pm 10.41 & 19.11-55.93 \\ 86.50 \pm 7.00 & 74.00-97.00 \\ 1208.51 \pm 473.34 & 278.83-1889.47\end{array}$

Intramale $C V$ in sperm morphometry (\%)

Head width

$3.37 \pm 0.54$

$2.48-4.65$

Head length

$2.92 \pm 0.51$

$4.56 \pm 0.78$

$2.12-3.99$

Head area

Head perimeter

Head ellipticity (length/width)

$2.31 \pm 0.44$

$4.34 \pm 0.69$

$1.31 \pm 0.38$

$1.33 \pm 0.41$

$2.47 \pm 0.53$

$1.76 \pm 0.50$
$3.36-5.80$

$1.56-3.06$

$3.45-6.21$

$0.88-2.16$

$0.91-2.38$

$1.92-3.74$

$1.26-2.91$
Principal plus terminal piece length

$\mathrm{VAP}=$ average path velocity; $\mathrm{VCL}=$ curvilinear velocity; $\mathrm{VSL}=$ straight linear velocity;

$6 \mathrm{SD}=$ standard deviation; $\mathrm{CV}=$ coefficient of variation.

7

8 


\section{Table 2 (on next page)}

Results of the principal component analysis (PCA) to determine overall sperm velocity.

$\mathrm{VAP}=$ average path velocity; $\mathrm{VCL}=$ curvilinear velocity; $\mathrm{VSL}=$ straight linear velocity; $\mathrm{PC}=$ principal component. 
1

2

\begin{tabular}{lcc}
\hline \multirow{2}{*}{ Sperm velocity variables } & \multicolumn{2}{c}{ PC1 loadings } \\
\cline { 2 - 3 } & \multicolumn{2}{c}{ eigenvectors } \\
\hline VAP & 0.991 & $<0.0001$ \\
VCL & 0.590 & 0.0127 \\
VSL & 0.856 & $<0.0001$ \\
& & \\
Variance explained $(\%)$ & 68.767 & \\
Eigenvalue & 2.063 & \\
\hline
\end{tabular}

Table 2. Results of the principal component analysis (PCA) to determine sperm velocity.
Principal components with an eigenvalue $>1$ are shown. PC1 loadings (i.e. eigenvectors and $P$ values) are correlation coefficients between the PC1 scores and the original variables of sperm velocity (VAP, VCL, and VSL). The results for the PC2 and PC3 were: PC2 (eigenvalue: 0.906; variance explained: $30.204 \%$ ) and PC3 (eigenvalue: 0.031; variance explained: $1.029 \%$ ). VAP= average path velocity; $\mathrm{VCL}=$ curvilinear velocity; $\mathrm{VSL}=$ straight linear velocity $; \mathrm{PC}=$ principal component. 